\title{
A CONCEPTUAL FRAMEWORK FOR A SUSTAINABLE PRODUCT DEVELOPMENT COLLABORATORY TO SUPPORT INTEGRATED SUSTAINABLE DESIGN AND MANUFACTURING
}

\author{
Kyoung-Yun Kim. \\ Department of Industrial and Systems Engineering \\ Wayne State University \\ Detroit, Michigan, USA \\ Email: kykim@eng.wayne.edu \\ Gül E. Okudan Kremer \\ School of Engineering Design \\ \& Department of Industrial and Manufacturing Eng. \\ The Pennsylvania State University \\ University Park, Pennsylvania, USA \\ Email: gek3@engr.psu.edu \\ Ratna B. Chinnam \\ Department of Industrial and Systems Engineering \\ Wayne State University \\ Detroit, Michigan, USA \\ Email: r_chinnam@wayne.edu
}

\author{
Karl R. Haapala \\ School of Mechanical, Industrial, and Manufacturing Eng. \\ Oregon State University \\ Corvallis, Oregon, USA \\ Email: haapalak@engr.orst.edu \\ Ekrem Alper Murat \\ Department of Industrial and Systems Engineering \\ Wayne State University \\ Detroit, Michigan, USA \\ Email: amurat@wayne.edu \\ Leslie F. Monplaisir \\ Department of Industrial and Systems Engineering \\ Wayne State University \\ Detroit, Michigan, USA \\ Email: Leslie.Monplaisir@wayne.edu
}

\begin{abstract}
This paper presents a research effort that is underway to integrate product, manufacturing process, and supply chain models to optimize product design variants in terms of costs and environmental impacts. Integrated sustainable design and manufacturing requires multidisciplinary knowledge from various industrial domains to design and manufacture environmentally-responsible products. Sustainable design should consider life cycle costs and environmental impacts, including those related to materials and energy requirements during the manufacturing, use, and end-of-life phases of a product's life. This paper discusses important technological requirements in product architecture and integrated optimization to realize integrated sustainable design and manufacturing. Finally, this paper introduces a scalable design environment, called the Sustainable Product Development Collaboratory, which can convey sustainability principles in the context of product architectural design, manufacturing, assembly, and supply chain decisions to designers. Potential benefits of this platform are also discussed.
\end{abstract}

\section{KEYWORDS}

Sustainable design and manufacturing, Cyberinfrastructure, Collaboratory, Integrated optimization, Life cycle assessment

\section{INTRODUCTION}

Researchers and practitioners alike recognize that a majority of product cost, quality, and sustainability aspects (economic, social, and environmental) are established during design; however, mainstream product development has struggled to integrate manufacturing concerns into the design stage. Consumers are demanding more environmentally sustainable products, motivated by increased awareness of potentially adverse product environmental impacts. Furthermore, environmental regulations have been enacted globally that affect U.S. businesses. Thus, product manufacturers see a pressing need to set, assess, and achieve sustainability goals.

Over the past several years, significant research emphasis has placed on sustainability. Allen et al. [1] describe the emerging grassroots activities for sustainable design and manufacturing. However, few tools and structured methods exist that can be readily integrated into 
industrial sustainable design and manufacturing efforts. Though several industrial ecology and life cycle analysis tools have been developed to support such efforts, they are primarily based on databases of economic and process information, which facilitate higher, systems-level analyses. Thus, the level of detail is often not sufficient to capture product design features and their relationships with manufacturing processes throughout a facility or across the supply chain.

Recently published studies focusing on integrating downstream concerns through design for X (DfX) methods, e.g., design for manufacturing and design for environment, have been found to largely address only individual DfX concepts. In addition, most studies examine these effects through specific case studies and/or scenario evaluation. The limitations in the current state of the art includes a lack of scalable tools and technologies that can capture interdependencies between product designs and architecture, and manufacturing processes or requirements, and the sheer complexity of the overall task of jointly improving product design, manufacturing processes, and supply chain management through flexible and representative models and algorithms.

This paper discusses two important technological requirements (i.e., product architecture and integrated optimization) to realize integrated sustainable design and manufacturing. Before the discussion of these technological challenges, current technologies and approaches for product and environmental sustainability are first presented. Finally, a conceptual framework for a Sustainable Product Development Collaboratory is introduced. The Collaboratory is envisioned to benefit manufacturing industry in training future engineers in sustainable design and manufacturing, in addition to supporting sustainable engineering decision making.

\section{BACKGROUND}

A product's carbon footprint is becoming a prominent factor in decision making for environmental sustainability. Carbon footprint encompasses the total set of greenhouse gas (GHG) emissions (i.e., carbon dioxide, nitrous oxide, methane, hydrofluorocarbons, perfluorocarbons, and sulfur hexafluoride) that the product causes directly or indirectly [31]. It is estimated that about $72 \%$ of GHG emissions are related to household consumption, implying that consumer products and services, along with their supply chains, are a major contributor [12]. Matthews et al. [26] asserted that only $26 \%$ of total supply chain emissions have been identified and mitigated. Moreover, the increasing trend towards outsourcing may lead to substantial growth of the global carbon footprint. Growth is expected even without accounting for associated transportation, due to less efficient energy generation and manufacturing processes in developing nations $[2,11]$. Thus, methodologies are needed to support product and supply chain design for increased performance, reduced costs, and lower environmental impacts.

Integrated sustainable design and manufacturing requires multidisciplinary knowledge from various industrial domains to design and manufacture environment-friendly products. Sustainable design should consider costs and environmental impacts due to material and energy use and wastes and emissions from across all life cycle stages (i.e. material extraction and processing, manufacturing, use, and end of life). Traditionally, open-loop product manufacturing systems have been developed and implemented, which consider product development, production, and distribution, while excluding the consideration of product end of use [17]. In this open-loop based system, the boundary of design knowledge is restricted to a few industries that have been associated with the manufacture of the product. To fully integrate the design and manufacturing decision making for sustainable products, product assembly design and life cycle considerations should be jointly optimized.

\section{CURRENT TECHNOLOGIES/APPROACHES FOR PRODUCT AND ENVIRONMENTAL SUSTAINABILITY}

As interest in environmental sustainability increases, industrial ecology and life cycle assessment tools are being developed to support product design. Prior research efforts have examined ways to integrate downstream concerns into the design stage through design for X (DfX) concepts, e.g., design for manufacturing (DfM), design for assembly (DfA), and design for environment (DfE). To incorporate life cycle environmental issues into the product design process, Ljungberg [25] provided guidelines to minimize materials, energy, emissions, and toxic elements over the life of a product, while maximizing renewable resource use, recyclable materials, energy efficiency, and product life. Ijomah et al. [16] incorporated process aspects and provided Design for Remanufacturing (DfRem) guidelines, which involve materials, assembly techniques, and product structure aspects. Howarth and Hadfield [15] developed a two-part Bournemouth University model for designers to review the sustainability of a product in the detail design phase. Waage [32] presented a four-phase process for achieving sustainable designs. These phases comprise establishing the sustainability context, defining the sustainability issues, assessing and acting, and receiving feedback. The resultant guidelines can be used during design conceptualization.

An approach to achieving sustainable design is the Design for Sustainability Matrix (DfSM), which analyzes the functional and environmental profile of a product [29]. A recent review by Chiu and Okudan $[4,5]$ identified 12 different tools (guideline sets, metrics, mathematical models, and methods) for Design for Environment (DfE) and Design for Sustainability (DfS). Kraines et al. [22, 23] has presented a semantic search engines that can help users to link to integrate fragmented knowledge in the field of industrial ecology. Their approach focuses on knowledge sharing and reuse for environmental assessment. However, it is still unclear how the architectural design decision will affect the environmental performance of conceptual design variants.

Although the ultimate environmental impact over the life of the product can never be judged with great accuracy due to high product-to-product variability at each stage, life cycle assessment (LCA) has emerged as a comparative method to judge amongst competing design alternatives on an environmental basis. An LCA proceeds by first defining the goal and scope of the study [7]. A critical barrier to LCA studies is the time-intensive nature of understanding and gathering data for each process across the life cycle, which is the second stage of the LCA, or completing a life 
cycle inventory (LCI). Thus, establishing the proper boundary and scope is vital to completing the study and providing meaningful results. Previously defined LCIs are sometimes available that represent a life cycle process of interest well. In other cases, process data must be collected or process models developed to estimate materials and energy inputs and outputs.

TABLE 1. SEVERAL CURRENT LCA TOOLS AND DATABASES

\begin{tabular}{|c|c|c|}
\hline $\begin{array}{l}\text { Tools and } \\
\text { Databases }\end{array}$ & Developer & Description \\
\hline $\mathrm{GaBi}$ & $\mathrm{PE}$ International GmbH & \multirow{5}{*}{$\begin{array}{l}\text { Assist product } \\
\text { environmental life } \\
\text { cycle assessment } \\
\text { (LCA) }\end{array}$} \\
\hline SimaPro & PRé Consultants B.V. & \\
\hline openLCA & GreenDeltaTC GmbH & \\
\hline TEAM & Ecobilan - PricewaterhouseCoopers & \\
\hline EIO-LCA & $\begin{array}{l}\text { Green Design Institute, Carnegie } \\
\text { Mellon University }\end{array}$ & \\
\hline Umberto & Ifu Hamburg GmbH & \multirow{3}{*}{$\begin{array}{l}\text { Assist substance } \\
\text { and material flow } \\
\text { analysis } \\
\text { (SFA/MFA) }\end{array}$} \\
\hline $\begin{array}{l}\text { Sankey } \\
\text { Editor }\end{array}$ & STENUM GmbH & \\
\hline STAN & Vienna University of Technology & \\
\hline ecoinvent & $\begin{array}{l}\text { Swiss Centre for Life Cycle } \\
\text { Inventories }\end{array}$ & \multirow{3}{*}{$\begin{array}{l}\text { Compile process } \\
\text { input/output data } \\
\text { for materials and } \\
\text { energy }\end{array}$} \\
\hline US LCI & $\begin{array}{l}\text { U.S. National Renewable Energy } \\
\text { Laboratory }\end{array}$ & \\
\hline DEAM & Ecobilan - PricewaterhouseCoopers & \\
\hline
\end{tabular}

Once appropriate LCIs are identified or constructed, the designer is confronted with the challenge of translating process information into measures of environmental impact. Several methods have been devised to assist in this process of impact assessment. Thus, the third LCA stage, Impact Assessment, often accounts for such impacts as ozone layer depletion, ecotoxicity, and acidification, known as midpoint indicators. To compare alternatives based on a single score, levels of impact can be normalized or weighted and aggregated. This process requires both expert knowledge and a certain level of subjectivity to establish weightings. Finally, the designer or design team can interpret the results to determine the relative influence of various product and process design changes on the environment. Table 1 summarizes several LCA tools and databases available.

To a large extent, limitations in the state of the art can be expressed as: 1) a lack of scalable tools and methods that can capture interdependencies between product architecture and process requirements across the life cycle, and 2) the sheer complexity of jointly improving the design and life cycle processes through flexible models and algorithms. Thus, an effort is underway to integrate product, manufacturing process, and supply chain models to optimize product design variants in terms of costs and environmental impacts through the Sustainable Product Development Collaboratory, as described in the following sections.

\section{PRODUCT DESIGN VARIANT ARCHITECTURE OPTIMIZATION}

AND

Many existing products are not remanufacturable since design has typically focused on functionality and cost at the expense of environmental issues [8]. There is an urgent need to develop strategies and tools, particularly design tools, databases, or knowledge-based systems, to assist the integration of environmental considerations at the product design stage $[10,27]$. One critical step at this stage is the determination of the product architecture, which is a description of how the functional elements of a product are allocated to components or sub-systems.

Integral, modular, and hybrid architectures are considered as the main product architecture categories. Because a modular architecture facilitates the standardization of components and increased product variety [9], modular designs have been applied extensively to develop complex products. While the advantages of modularity vary in different industries, examples of common ones are [19]: 1) reduction in product development time; 2) customization and upgrade; 3 ) cost efficiencies due to amortization; and 4) design standardization. Indeed, a modular architecture can enable design for disassembly (DFDis), and design for remanufacturing (DFRem), which have a strong influence on product environmental impact, among other benefits $[6,16]$.

For environmentally conscious product design, modular design has been proven to be an effective approach. It can group components into easily detachable modules, and separate components with different materials into different modules to facilitate reuse, recycling, and disposal [30]. However, most studies of sustainable product design are conducted independently from the supply chain and ignore the potential impact of product modular structure on supply chain network structure. Thus, there are research gaps to be filled by linking the architecture exploration with a supply chain optimization module.

The authors are currently developing the Collaboratory to explore design architecture changes to improve disassembly and remanufacturability of products to minimize the environmental impacts. Examples of architecture modifications for remanufactured products are numerous and varied [33]. Typically, studies consist of analyzing the problems of remanufacturing linked to the architecture, and propose, but do not implement design modifications.

\section{INTEGRATED OPTIMIZATION}

\section{Integrated life cycle assessment:}

While sustainability encompasses economic, environmental, and social factors, current Collaboratory development efforts are focused on understanding the effect of product design changes on life cycle costs and environmental impacts. A design modification can involve the specification of a different material, a change to the part geometry, or requirement of a different subsystem, for example. In turn, these changes will have a ripple affect across the material and parts supply chain, as well as into how the product is ultimately used and treated at the end of its useful life. Thus, there is a need to have a life cycle assessment tool to calculate the estimated environmental impact of design variants.

A single design variant represents a set of materials, components, and assemblies each produced by a sequence 
of processes by various actors throughout the supply chain. Current LCI databases contain inventory data for representative materials extraction and processing, as well as transportation activities, while there is a dearth of information concerning individual unit manufacturing processes [28]. The Collaboratory will take advantage of available process input/output data, in addition to developing process models for unit manufacturing processes that are not well-represented. This tool will accordingly help designers understand and appropriately model processes associated with procurement, production, distribution, service, and end-of-life support activities at a resolution meaningful for guiding sustainable product development. Product life cycle trade-offs can be illustrated through metrics of cost, responsiveness (i.e., supply chain replenishment lead time as a function of supply/distribution network configuration and procurement/distribution policies), and environmental impacts.

\section{Supply chain optimization:}

While there has been recent interest in the operations research community into the connection between the supply chain and its carbon footprint, the aim of such efforts is often to adjust operational decisions and improve collaborations among supply chain partners to address carbon emissions concerns [3]. However, product design decisions, which are key in determining the efficiency of supply chain operations and resulting carbon emissions, are often overlooked. Hence, there is a need for a tool to integrate scalable models representing the inter-dependency between the design variants and down-stream processes including the remanufacturing and reverse logistics operations. The Collaboratory will enable building, revising and querying product design-supply chain models through textual declarations and mathematical relationships. For example, a user can input a restriction constraint for total carbon emission in the form of text-based statements, e.g., "injection molded components" of the "design variant" should not exceed " $4 \mathrm{~kg}$ of $\mathrm{CO} 2$." This text-based approach for developing and modifying the models improves the interpretation of results in terms of carbon emission tradeoffs. The users can view and modify the models in mathematical formulation and relate the conceptual declarations to mathematical formulations in terms of decision variables (e.g., binary, continuous) and relations (e.g., logical).

Joint optimization models are under development by the team in the form of multi-criteria mixed-integer programs for selection of design variants and optimization for down-stream processes. Examples of the common models for downstream supply chain processes are network flow models and capacitated facility selection and sourcing models. These models are created, stored, and shared in the cyber-environment, and solutions are carried out on servers running open-source algorithms. The post-solution analysis allows users to optimize the downstream processes for a design alternative selected or allow the module solvers to select the best design alternative. To facilitate trade-off analysis, the model outputs for a selected design alternative are displayed with multiple criteria, e.g., target customer needs, procurement cost, production cost, transportation cost and carbon emissions. The non-dominated designs will be presented through graphical illustrations (e.g. carbon emission vs. cost) for better understanding of sustainability tradeoffs in selecting among design alternatives.

\section{SUSTAINABLE PRODUCT DEVELOPMENT COLLABORATORY CONCEPTUAL FRAMEWORK}

A collaborative and scalable framework will maximize the synergy of integrating the architecture design, life-cycle assessment, and supply chain optimization. Figure 1 illustrates the conceptual framework to be realized by the Sustainable Product Development Collaboratory. In the framework, various modules and the knowledge repository are integrated into a service-oriented architecture that is accessible via the Internet. The Collaboratory modules exploit existing and evolving design repositories, including component specifications, interaction matrices, and graphical grammar rules, to generate conceptual design variants and component sets. The web-based design interface communicates with the conceptual modeler, which displays the design component sets and variants. The web interface reads and updates any changes made in the conceptual design variants and components set. The changed information is captured as updates in the knowledge warehouse accordingly. This framework is based on a life cycle analysis approach to evaluate user needs and to analyze product architecture variants by balancing the impact on life cycle and supply chain.

The assembly design, design requirements, and manufacturing/assembly ontology provide input to the formal description of the shared conceptualization in the collaboratory. The ontology facilitates efficient selection of the best subset of design variants for their impact on procurement, manufacturing, assembly, distribution, sustainment, collection, and disposal. The collaboratory warehouse stores any findings/refinements from the modules and the ontology manager updates ontologies based on the analyses and optimization results. 


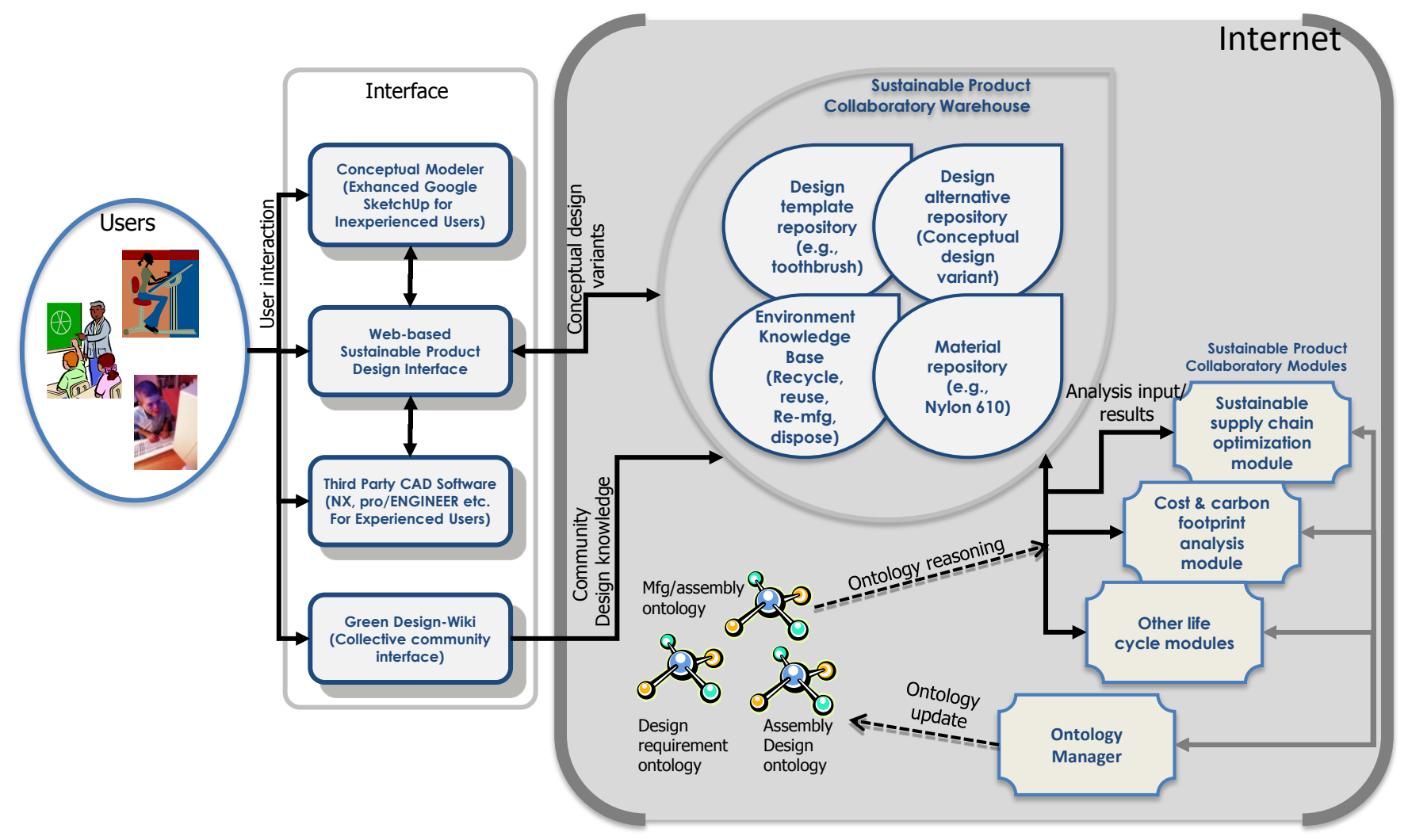

FIGURE 1. OVERALL ARCHITECTURE OF SUSTAINABLE PRODUCT DEVELOPMENT COLLABORATORY

For this framework, ontologies play as formal, explicit specifications of a shared conceptualization of product architecture variants. The ontology makes design knowledge machine-interpretable. Implicit product architecture and design requirement constraints will be explicitly represented using OWL (Web Ontology Language) and SWRL (Semantic Web Rule Language). In the past decade, ontologies have been actively studied in various research domains. Mylopoulos and $\mathrm{Yu}$ [18] surveyed the advantages and drawbacks of ontological engineering efforts, and classified knowledge representation into four broad categories: 1) static ontologies, 2) dynamic ontologies, and 3) intentional ontologies, which encompass the world of things that agents believe in, want, prove or disprove, and argue about, and 4) social ontologies, which cover social settings such as agents, positions, roles, authority, permanent organizational structures or shifting networks of alliances and interdependencies.

Horváth et al. [13.14] attempted to create an ontology for design features by classifying design concepts into entities, phenomena, and situations. Liang and Paredis [24] developed a part ontology to capture form, function, and behavior aspects in conceptual design. However, research gaps still exist in realizing a complete process to capture semantics of conceptual design variants and industrial ecology. In this conceptual framework, three main ontologies (i.e., assembly design, design requirement, and manufacturing/assembly) and associated semantic rules are under development by using OWL and SWRL [20, 21].

The Collaboratory's realization requires an architecture that can seamlessly integrate Collaboratory modules and ontologies, and share associated knowledge. A serviceoriented collaborative architecture can link the modules via the Internet to form a distributed Collaboratory environment. The intent of the service-oriented collaborative architecture is to incorporate different engineering services and make them available for transparent transactions in the Collaboratory. Services, processes that provides a functional use for a person, an application program, or another service in the system, should be specified from the functional aspect of service providers. To make an existing tool available online or to build a brand new tool for such a system, services associated with this tool should be defined. This architecture includes three core functional elements (i.e., service providers, service consumers, and the service manager). Once a service is registered at a central administrative manager, service manager, it is available within the whole system. When a service consumer within the system needs a service, it will request a lookup service from the service manager. If the service is available, the service consumer can request the service from the service provider with assistance from the service manager. Most importantly, this triangular service relationship should be built at run-time. The service consumer (client) does not know the name, the location, or even the way to invoke the service from the service provider (server) during the system and tools development period. Each node in this network can both require and provide certain services; thus, it can be both a client and a server at different times. Since the client/server relationship is determined at run-time, the system is open for the future expansion and extension if more services become available. 


\section{CONCLUSIONS AND POTENTIAL BENEFITS OF THE COLLABORATORY}

The Sustainable Product Development Collaboratory is under development to explore design architecture changes to improve disassembly and remanufacturability of products to minimize life cycle costs and environmental impacts. For environmentally conscious product design, modular design has been proven to be an effective approach. However, most studies of sustainable design are conducted independently from supply chain development, and ignore the potential impact of product modular structure on supply chain network structure.

While there has been recent interest in the operations research community into the connection between the supply chain and its carbon footprint, the aim of such efforts is to adjust operational decisions and improve collaboration among supply chain partners to address carbon emissions concerns. However, the product design decisions are key in determining the efficiency of supply chain operations and resulting carbon emissions. The Collaboratory is expected to support the development of products and related supply chains for increased performance, reduced costs, and reduced environmental impacts, e.g., smaller carbon footprint.

The Sustainable Product Development Collaboratory is intended to deliver a cyber-based tool and interactive elearning platform. It will educate users in sustainable design and manufacturing by demonstrating the effects of different product designs on supply chain costs and environmental impacts. It is expected to create an evolving design repository, promote empirical/experimental investigation to model life cycle costs and environmental performance, and advance methods for design variants and supply chain optimization, while being readily available and reusable across a spectrum of learners (K-12 students, university students, and practitioners). Under the new paradigm, users will gain holistic experience facilitated by knowledge sets of product architecture and environmental performance to undertake sustainable design and manufacturing.

\section{ACKNOWLEDGEMENTS}

The research is based on the work supported by the National Science Foundation under Grant No. OCI-1041380.

\section{REFERENCES}

[1] Allen D, Allenby B, Bridges M, Crittenden J, Davidson C, Hendrickson C, Matthews S, Murphy C, Pijawka D (2008) Benchmarking Sustainable Engineering Education: Final Report. EPA Grant Number: X383235101-0.

[2] Anastas PT, Zimmerman JB (2003) Design through the 12 Principles of Green Engineering. Environmental Science and Technology 37, 94-101.

[3] Benjaafar S, Li Y, Daskin M (2010) Carbon Footprint and the Management of Supply Chains: Insights from Simple Models. Working Paper, University of Minnesota. $1-37$

[4] Chiu MC, Okudan GE (2009a) An Integrative Methodology for Product and Supply Chain Design Decisions at the Product Design Stage. Journal of Mechanical Design (under review).

[5] Chiu MC, Okudan GE (2009b) Investigation of the Applicability of DfX Tools during Design Concept Evolution: A literature Review. Journal of Product Development (under review).
[6] U.S. Congress (1992) Green Products by Design: Choices for a Cleaner Environment. Office of Technology Assessment

[7] Curran MA (2006) Life Cycle Assessment: Principles and Practice. EPA/600/R-06/060 U.S. Environmental Protection Agency, Cincinnati, $\mathrm{OH}$.

[8] Ferrer G (2001) On the widget remanufacturing operation. European Journal of Operational Research 135, 373-393.

[9] Gershenson JK, Prasad GJ, Zhang Y (2003) Product modularity: definitions and benefits. Journal of Engineering Design 14, 295-313.

[10] Gupta S, Okudan G (2008) Computational Modularized Conceptual Designs with Assembly and Variety Considerations. Journal of Engineering Design 19, 533 551.

[11] Herrmann IT, Hauschild MZ (2009) Effects of globalisation on carbon footprints of products. CIRP Annals - Manufacturing Technology 58, 13-16.

[12] Hertwich EG, Peters GP (2009) Carbon footprint of nations: A global, trade-linked analysis. Environmental Science and Technology 43, 6414-6420.

[13] Horváth I, Van Der Vegte WF (2003) Nucleus-Based Product Conceptualization-Part 1: Principles and Formalization, International Conference on Engineering Design, August 19-21, Stockholm.

[14] Horváth I, Pulles JPW, Bremer AP, Vergeest JSM (1998) Towards an Ontology-based Definition of Design Features. SIAM Workshop on Mathematical Foundations for Features in Computer Aided Design, Engineering, and Manufacturing.

[15] Howarth G, Hadfield M (2006) A sustainable product design model. Materials and Design 27, 1128-1133.

[16] Ijomah WL, McMahon CA, Hammond GP, Newman ST (2007) Development of robust design-forremanufacturing guidelines to further the aims of sustainable development. International Journal of Production Research 45, 4513-4536.

[17] Jayal AD, Badurdeen F, Dillon Jr. OW, Jawahir IS (2010) Sustainable manufacturing: Modeling and optimization challenges at the product, process and system levels. CIRP Journal of Manufacturing Science and Technology 2 144-152.

[18] Mylopoulos JJ, Yu E (2004) Ontologies for Knowledge Management: An Information Systems Perspective. Knowledge and Information Systems 6 380- 401.

[19] Kamrani AK, Salhieh SM (2002) Product Design for Modularity. Norwell, Massachusette, Kluwer Academic Publishers.

[20] Kim KY, Chin S, Kwon O, Ellis RD (2009) Ontologybased Integration of Morphological Information of Assembly Joints for Network-based Collaborative Assembly Design. Artificial Intelligence for Engineering Design, Analysis and Manufacturing (AI EDAM) 23, 7188.

[21] Kim KY, Yang HJ, Kim DW (2008) Mereotopological Assembly Joint Information Representation for Collaborative Product Design. Robotics and ComputerIntegrated Manufacturing 24, 744-754.

[22] Kraines S, Batres R, Kemper B, Koyama M, Wolowski V (2006) Internet-based Integrated Environmental Assessment Part II - Semantic Search Based on Ontologies and Agent Systems for Knowledge Discovery. Journal of Industrial Ecology 10, 37-60.

[23] Kraines S, Batres R, Koyama M, Wallce D, Komiyama H (2005) Internet-based Integrated Environmental Assessment - Using Ontologies to Share Computational Models. Journal of Industrial Ecology 9, 31-50. 
[24] Liang VC, Paredis CJJ (2004) A Port Ontology for Conceptual Design of Systems. ASME Jr. of Computing and Information Science in Engineering 4, 206-217.

[25] Ljungberg LY (2007) Materials selection and design for development of sustainable products. Materials and Design, 28, 466-479. Market Share Reporter (2007) Market Share Reporter: An Annual Compilation of Reported Market Share Data on Companies, Products, and Services. Gale Research Inc. Detroit, MI, USA

[26] Matthews HS, Hendrickson CT, Weber CL (2008) The importance of carbon footprint estimation boundaries. Environmental Science and Technology 42, 5839-5842.

[27] Nissen U (1995) A Methodology for the development of cleaner products. Journal of Cleaner Production 3, 83-87.

[28] Ramani K, Ramanujan D, Bernstein WZ, Zhao F, Sutherland J, Handwerker C. Choi J.-K., Kim, H., and Thurston, D., "Integrated Sustainable Life Cycle Design: A Review," J. Mech. Des., Vol. 132, 2010, 091004.

[29] Short TD, Lynch CA (2004) Beyond the eco-functional matrix - Design for sustainability and the Durham methodology. Design and Manufacture for Sustainable Development conference 2004, September 1-2, Loughborough, UK.

[30] Sosale S, Hashemian M, Gu P (1997) Product modularization for reuse and recycling. Dallas, TX, USA, ASME.

[31] UK

Carbon

Trust, http://www .carbontrust.co.uk/solutions/ CarbonFootprinting/what_is_a_carbon_footprint.

[32] Waage SA (2007) Re-considering product design: a practical "road-map" for integration of sustainability issues. Journal of Cleaner Production 15, 638-649.

[33] Zwolinski P, Lopez-Ontiveros MA, Brissaud D (2006) Integrated design of remanufacturable products based on product profiles. Journal of Cleaner Production 14, 13331345 . 